\title{
Study on Grain Refinement of Nickel-Based Filler Metal 52M Microstructure by Pulse TIG Welding
}

\author{
X.H. Zhang, J.Q. Chen*, K. Zhang and H. Chen \\ School of Materials Science and Engineering, Southwest Jiaotong University, No. 111 of Two Ring \\ Road North Section, Chengdu, China \\ ${ }^{*}$ Corresponding authors. E-mail addresses: manbu880@163.com
}

Keywords: FM-52M, weld grain refinement, pulse TIG, welding parameters.

\begin{abstract}
FM-52M, a kind of filler metal matched for Inconel 690, is widely applied in critical components of nuclear power plant. In this work, the effect of the microstructure refinement of FM-52M was studied through pulse TIG welding. First, a serial of bead welds under different welding parameters were conducted to elucidate the effect on the grain refinement of weld. Optical microscope and electron backscattered diffraction were used to analysis the interaction between welding parameters and average grain diameter. The results revealed that the grain orientation and microstructure have a great change by introducing the pulse current. In addition, the influence of welding process parameters on the weld grain size is obviously different. In a reasonable range of parameter, the grains became smaller with the peak current increasing. Furthermore, pulse frequency and duty cycle had the same effect on microstructure. In contrast, a scent of grain coarsening appeared with base current increasing.
\end{abstract}

\section{Introduction}

With the excellent resistance to stress corrosion cracking and high temperature performance, nickel-based alloy becomes a significant material extensively used in nuclear industry [1, 2]. ERNiCrFe-7A (filler metal 52M) is the companion filler metal for Inconel 690 welding. Owing to the content increase of $\mathrm{B}$ and $\mathrm{Nb}$ and reduce of $\mathrm{Al}$ and $\mathrm{Ti}$, the resistance to ductility-dip cracking (DDC) was enhanced for FM-52M [3-5]. Since the grain size of the weld has significant influence on homogeneity and crack deflection [6-9], it shapely affects the DDC initiation and propagation [10]. Besides, diverse welding process will bring different microstructure morphology, it is pressingly necessary to investigate the exact effects of welding method and its parameters on microstructure.

Gas metal arc welding possesses high deposition rate, high welding speed and deep penetration due to high heat input relative to tungsten inert gas (TIG) welding [11]. However, excessive heat input readily leads to welding defects. Presently, TIG welding process is one of the most mature welding technique which has been widely applied to Ni-based superalloy, Ti-alloys and Al-alloys, to produce the good quality welds [11-13]. In pulse TIG (PTIG) process, the welding current is supplied in pulses instead of a constant magnitude. The purpose of pulsing is primarily to achieve maximum penetration without excessive heat build-up, by utilizing the peak current to penetrate deeply and then allowing the weld pool to dissipate heat and solidify at a base current [11, 14-16]. It has been reported [11, 13, 14] that the influence of pulse parameters on grain size and microstructure is very complex. Literature review did not conduct much work on the effect of pulse parameters (peak current, base current, pulse frequency and duty ratio) of PTIG welding process for Ni-based alloy on grain size and microstructure.

Table 1. Chemical composition of Inconel 690 and FM-52M (wt. \%).

\begin{tabular}{|c|c|c|c|c|c|c|c|c|c|}
\hline Materials & $\mathrm{Si}$ & $\mathrm{Fe}$ & $\mathrm{Co}$ & $\mathrm{Mn}$ & $\mathrm{C}$ & $\mathrm{Cr}$ & $\mathrm{Ni}$ & $\mathrm{P}$ & $\mathrm{S}$ \\
\hline Inconel690 & $<0.5$ & $8-12$ & $<0.1$ & $<0.5$ & $<0.04$ & $28-31$ & $\mathrm{Bal}$ & $<0.01$ & $<0.01$ \\
\hline FM-52M & 0.09 & 8.22 & 0.011 & 0.8 & 0.02 & 30.06 & 59.54 & 0.020 & 0.015 \\
\hline
\end{tabular}


Therefore, in this work, the aim of this study is to investigate the influence of PTIG welding processing parameters, such as peak current, base current, frequency and duty cycle, on grain size and microstructure for Ni-based deposited metal of FM-52M. Optical microscope (OM) and electron backscattered diffraction (EBSD) were utilized to observe the microstructure and measure average diameter of weld grain by using Hayne line method. With optimization of the welding parameters, the performance of weld was enhanced by comparing grain size and homogeneity of weld, which would supply experimental guidance and reference for the industry application of Ni-based alloy.

\section{Experimental procedures}

The base metal employed in this study is $4 \mathrm{~mm}$ thick Inconel 690, overlaying welded with the companion filler metal $52 \mathrm{M}(\Phi 0.9 \mathrm{~mm})$. The chemical composition of the base material and filler metal are listed in table 1 . The processes of TIG and PTIG were performed separately to fabricate a 3 layers overlay on base metal for subsequent testing. The processing parameter of TIG and PTIG are depicted at table 2 .

Table 2. Welding parameters.

\begin{tabular}{|c|c|c|c|c|c|}
\hline Number & $\begin{array}{c}\text { Peak current } \\
\left(\mathrm{I}_{\mathrm{p}} / \mathrm{A}\right)\end{array}$ & $\begin{array}{c}\text { Base current } \\
\left(\mathrm{I}_{\mathrm{b}} / \mathrm{A}\right)\end{array}$ & $\begin{array}{c}\text { Frequency } \\
(\mathrm{f} / \mathrm{Hz})\end{array}$ & $\begin{array}{c}\text { Duty cycle } \\
(\mathrm{D} / \%)\end{array}$ & $\begin{array}{c}\text { Feed rate } \\
\left(\mathrm{v} / \mathrm{m}^{-\mathrm{min}^{-1}}\right)\end{array}$ \\
\hline 1 & 100 & $20(20 \%)$ & 4 & $50 \%$ & 0.50 \\
\hline 2 & 50 & $20(40 \%)$ & 4 & $50 \%$ & 0.26 \\
\hline 3 & 80 & $20(25 \%)$ & 4 & $50 \%$ & 0.42 \\
\hline 4 & 80 & $50(63 \%)$ & 4 & $50 \%$ & 0.42 \\
\hline 5 & 80 & $80(100 \%)$ & 0 & $50 \%$ & 0.42 \\
\hline 6 & 80 & $40(50 \%)$ & 4 & $50 \%$ & 0.42 \\
\hline 7 & 80 & $40(50 \%)$ & 12 & $50 \%$ & 0.34 \\
\hline 8 & 80 & $40(50 \%)$ & 4 & $60 \%$ & 0.42 \\
\hline 9 & 80 & $48(60 \%)$ & 4 & $20 \%$ & 0.42 \\
\hline
\end{tabular}

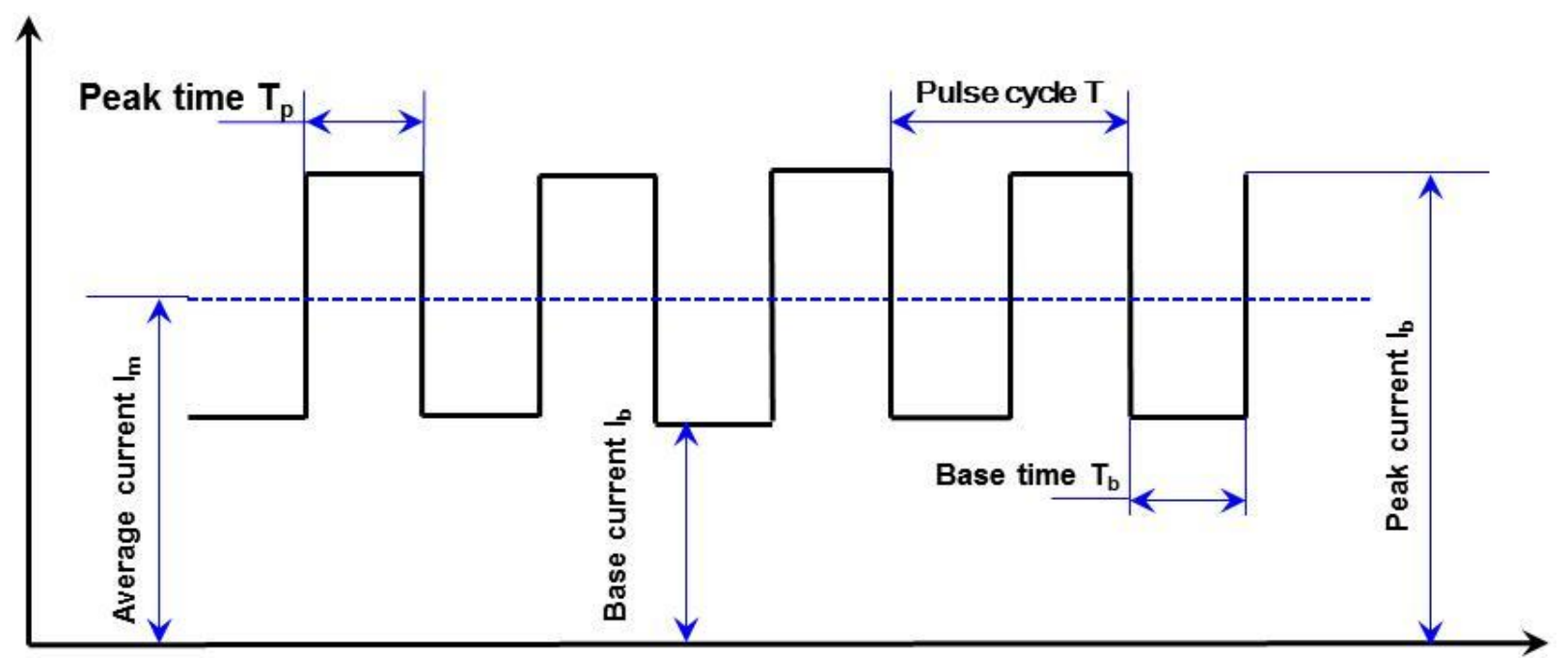

Figure 1. Schematic diagram of the variation of welding current with time.

The PTIG cladding was carried out on Fronius digital welder. A schematic diagram of the variation of welding current with time is depicted in figure 1 . The base metals were polished and cleaned with acetone in preparation before the welding. Prior to the deposition, oxide films generated on surface of each pass were eliminated to avoid defect. Pure argon $(99.99 \%$ Ar) gas was used for shielding during deposition and the flow rate was $10 \mathrm{~L} / \mathrm{min}$. The welding speed was $3 \mathrm{~cm} / \mathrm{min}$. 
The specimens for observation were taken from the middle part of the overlays by using electrodischarge machining. Both sides of the specimens were properly polished, and etched by $10 \%$ chromic acid for $30 \mathrm{~s}$ under $5.5 \mathrm{~V}$ for the $\mathrm{OM}$ observation. Furthermore, the samples were electropolished in a mixture of $20 \%$ perchloric acid and $80 \%$ alcohol with DC $12 \mathrm{~V}$ at room temperature, followed by EBSD analysis.

\section{Results and discussion}

\subsection{Microstructure comparison of TIG with PTIG}

Figure 2 shows the microstructure characteristic of weld bead fabricated with TIG and PTIG, respectively. Owing to majority columnar dendrites grow almost vertically to fusion line, a perspective of cross-section is selected for observation. According to previous research [10], the primary dendritic arm spacing (PDAS) is determined by the heat input in the deposition. From figure $2 \mathrm{a}$ and $\mathrm{b}$, the average PDAS in the deposit PTIG (figure $2 \mathrm{~b}$ ) is smaller than that in the deposit TIG (figure 2a). It was resulted by the lower heat input of PTIG compared to conventional TIG. That means the PTIG welding method makes the texture of FM-52M claddings more uniform and dense which is conducive to control the Ni-based alloy defects of welding.

EBSD inverse pole figure (IPF) depicts the grain crystallographic orientation and grain size distribution, as shown in figure $2 c$ and $d$. By contrast with IPF of TIG welding (figure 2a), it could be found in deposit PTIG (figure 2b) that the grain orientations are dispersed and grain size is smaller. Since the electromagnetic vibration of pulse current in PTIG welding, coarse dendrite grain could be broken to generate small grains. Simultaneously, some dynamic recrystallization grains were formed on the boundaries of fragments in the initial large grains under arc pressure. Therefore, the grains were refined and grain orientations became disordered. According to the previous study [17], the disorder grain orientation and small grain size help to reduce the DDC susceptibility. Therefore, PTIG welding process could alleviate the DDC susceptibility.
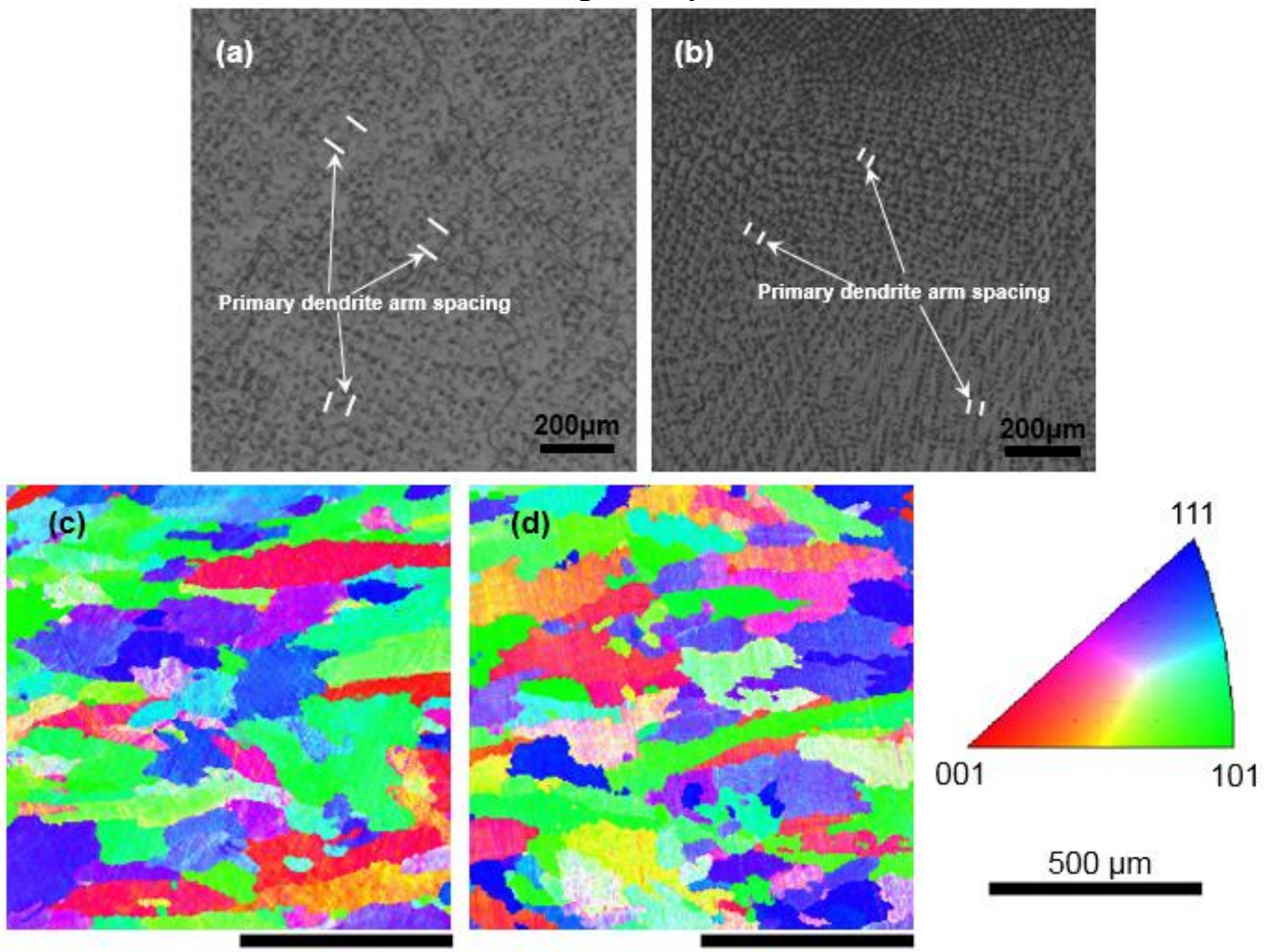

Figure 2. Optical micrographs and EBSD characterisation of FM-52M deposits welded by conventional TIG and PTIG, respectively. (a) 90 A, 0 Hz (TIG) ; (b) 90 A, 4Hz (PTIG); (c) IPF of TIG; (d) IPF of PTIG. 
Table 3. Welding parameters and grain size under different peak current.

\begin{tabular}{|c|c|c|c|}
\hline $\begin{array}{c}\text { Peak current } \\
\mathrm{I}_{\mathrm{p}} / \mathrm{A}\end{array}$ & $\begin{array}{c}\text { Base current } \\
\mathrm{I}_{\mathrm{b}} / \mathrm{A}\end{array}$ & $\begin{array}{c}\text { Duty cycle } \\
\mathrm{D}(\%)\end{array}$ & $\begin{array}{c}\text { Frequency } \\
\mathrm{f} / \mathrm{Hz}\end{array}$ \\
\hline 100 & 20 & 50 & 4 \\
\hline 50 & 20 & 50 & 4 \\
\hline
\end{tabular}
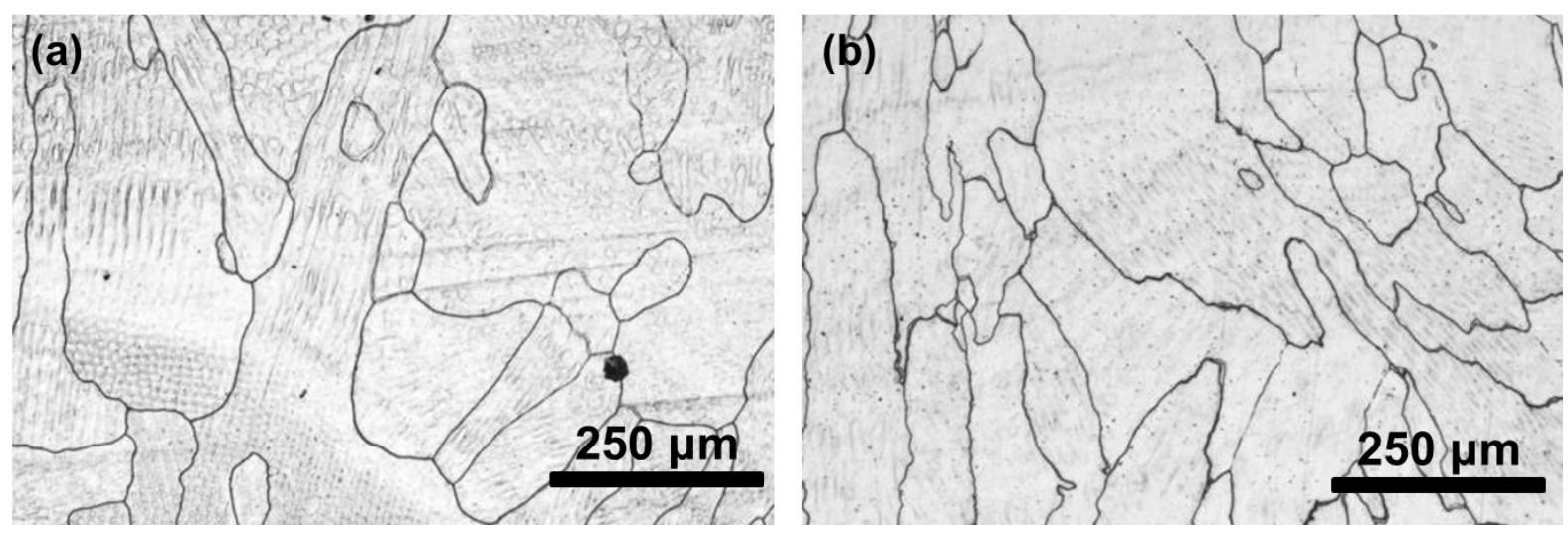

Figure 3. Metallographic structure under different peak current, (a) $50 \mathrm{~A}$, (b) $100 \mathrm{~A}$.

\subsection{Influence of operating parameters on grain}

The TIG welding operating parameters, such as current, voltage, welding speed, feed wire speed and so on, determines the dimension and shape of weld bead, due to the synergetic effects of these parameters[18]. According the previous researches [18, 19], various combinations of welding parameters can control the heat input during welding, and further generates different penetration, weld bead width and residual stress.

Effect of peak current

Welding parameters under different peak current and microstructure of the weld are shown in table 3 and figure 3 respectively. As shown in figure 3a, the grain is coarser and larger which results in reducing the numbers of grain when the peak current is $50 \mathrm{~A}$. The heat input for molten pool rised with the increasing of peak current to $100 \mathrm{~A}$, however the grain become finer and the average grain diameter is smaller. This change is attributed to the increase of plasma fluid force in axial and electromagnetic vibration of arc when the peak current is increasing. According to previous report [20, 21], the plasma fluid force has two functions to molten pool; One is an additional pressure generated during the arc-on time which leads to a significant increment of nucleation number and further prompts the grains become finer, the other is electromagnetic vibration which results in a forceful flow for metal in molten pool. The flow in molten pool has effects on nucleation [20]. First, some of the grains crystallized in the mushy zone are broken to form a new nucleation particle, which increases the nucleation rate. Meanwhile, heat dissipation of the molten metal in the solution pool is accelerated and further suppressing the dendrite growth which leads to prompting of the heterogeneous nucleation. Based on the analysis above, it is concluded that reasonable increasing peak current can refine weld grain of filler metal 52M during welding process.

Table 4. Welding parameters and grain size under different pulse frequency.

\begin{tabular}{|c|c|c|c|}
\hline $\begin{array}{c}\text { Peak current } \\
\mathrm{I}_{\mathrm{p}} / \mathrm{A}\end{array}$ & $\begin{array}{c}\text { Base current } \\
\mathrm{I}_{\mathrm{b}} / \mathrm{A}\end{array}$ & $\begin{array}{c}\text { Duty cycle } \\
\mathrm{D}(\%)\end{array}$ & $\begin{array}{c}\text { Frequency } \\
\mathrm{f} / \mathrm{Hz}\end{array}$ \\
\hline 80 & 80 & 50 & 0 \\
\hline 80 & 40 & 50 & 4 \\
\hline 80 & 40 & 50 & 12 \\
\hline
\end{tabular}




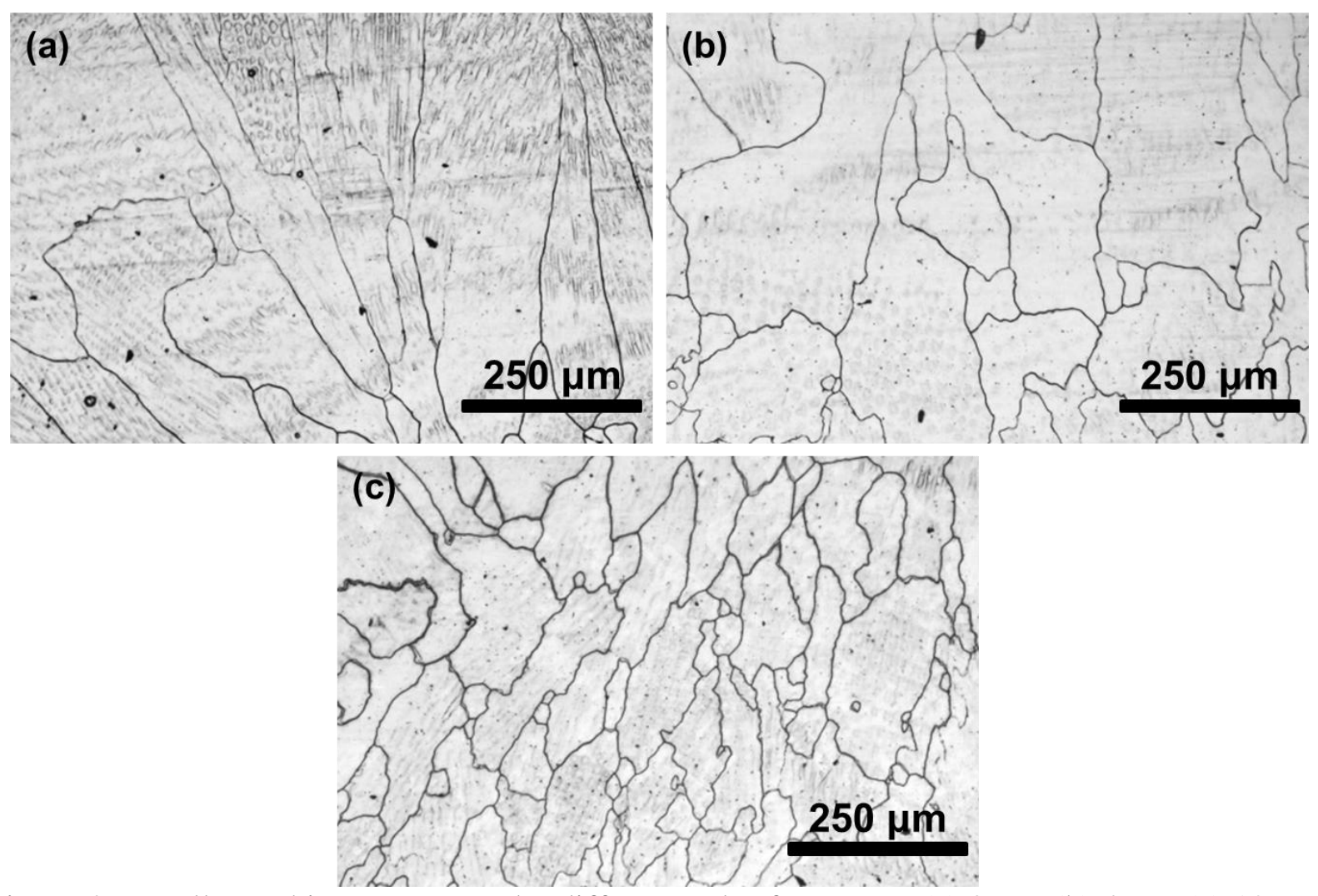

Figure 4. Metallographic structure under different pulse frequency, (a) $0 \mathrm{~Hz}$, (b) $4 \mathrm{~Hz}$, (c) $12 \mathrm{~Hz}$.

Effect of pulse frequency

As shown in figure 4 and table 4, a comparison was conducted to analysis the influence of different pulse frequency including convention TIG (pulse frequency is 0) and PTIG on weld grain size. From figure 4 , when the pulse frequency is 0 , the weld grain size is larger relative to frequency is 4 and 12 . Similarly. Observing the metallographic microstructure of frequency value is 4 and 12 could conclude the same rule. Because of the increasing with frequency, the contraction of arc becomes sharper which results in an rise of arc pressure and further increases the number of nucleation [22]. Furthermore, with increase of pulse frequency, the number of action times for plasma fluid force on the molten pool in axial direction caused by peak current would raise up. The plasma fluid force could induce intense electromagnetic stirring on molten pool, so that a breakage appears for crystallized grains, resulting in an increase in the number of weld grains. It concludes that increasing the pulse frequency in a reasonable range can refine the weld grains of Inconel 690 and companion filler metal 52M.

Table 5. Welding parameters and grain size under different base current.

\begin{tabular}{|c|c|c|c|}
\hline $\begin{array}{c}\text { Peak current } \\
\mathrm{I}_{\mathrm{p}} / \mathrm{A}\end{array}$ & $\begin{array}{c}\text { Base current } \\
\mathrm{I}_{\mathrm{b}} / \mathrm{A}\end{array}$ & $\begin{array}{c}\text { Duty cycle } \\
\mathrm{D}(\%)\end{array}$ & $\begin{array}{c}\text { Frequency } \\
\mathrm{f} / \mathrm{Hz}\end{array}$ \\
\hline 80 & 50 & 50 & 4 \\
\hline 80 & 20 & 50 & 4 \\
\hline
\end{tabular}

\section{Effect of base current}

A group of metallographic microstructure under different base current, $50 \mathrm{~A}$ and $20 \mathrm{~A}$, are shown in figure $5 \mathrm{a}$ and $\mathrm{b}$ separately, and the welding parameter is shown in table 5. According the figure 5b, the weld grain has smaller size and more quantity compared with figure $5 \mathrm{a}$. With the increase of base current, the weld grains have a tendency to become coarse. The explanation for this phenomenon is that the undercooling is decreased. It is reported that heat input for molten pool rises with the increasing of base current, and further leads to a decline of cooling rate in molten bath [21]. In contrast, the increasing of cooling rate enlarges both of nucleation and linear growth velocity, however the nucleation rate is bigger than linear growth velocity rate, which results in a grain refining by increasing the number of crystal nucleus. So the bigger base current produces higher heat input and 
further the increasing of heat input for molten pool have a tendency of weld grain growing. It could be concluded that small base current can help to refine the weld grains in 52M welding.
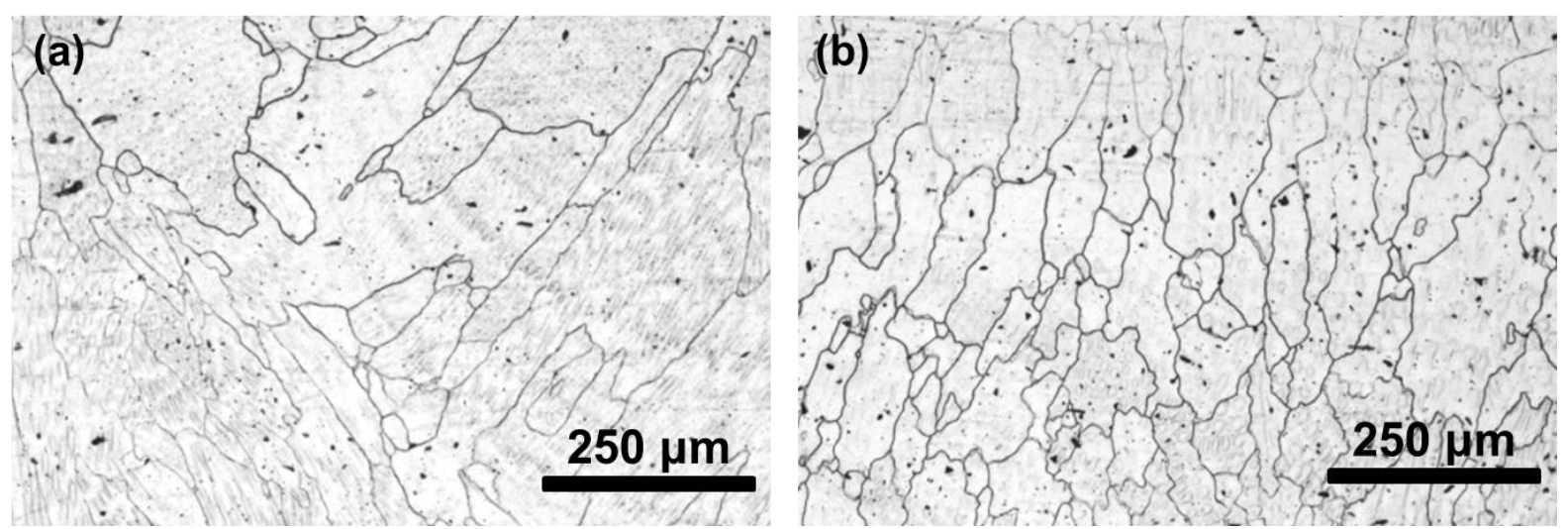

Figure 5. Metallographic structure under different base current, (a) $50 \mathrm{~A}$, (b) $20 \mathrm{~A}$.

Table 6 . Welding parameters and grain size under different duty cycle.

\begin{tabular}{|c|c|c|c|}
\hline $\begin{array}{c}\text { Peak current } \\
\mathrm{I}_{\mathrm{p}} / \mathrm{A}\end{array}$ & $\begin{array}{c}\text { Base current } \\
\mathrm{I}_{\mathrm{b}} / \mathrm{A}\end{array}$ & $\begin{array}{c}\text { Duty cycle } \\
\mathrm{D}(\%)\end{array}$ & $\begin{array}{c}\text { Frequency } \\
\mathrm{f} / \mathrm{Hz}\end{array}$ \\
\hline 80 & 40 & 60 & 4 \\
\hline 80 & 58 & 20 & 4 \\
\hline
\end{tabular}
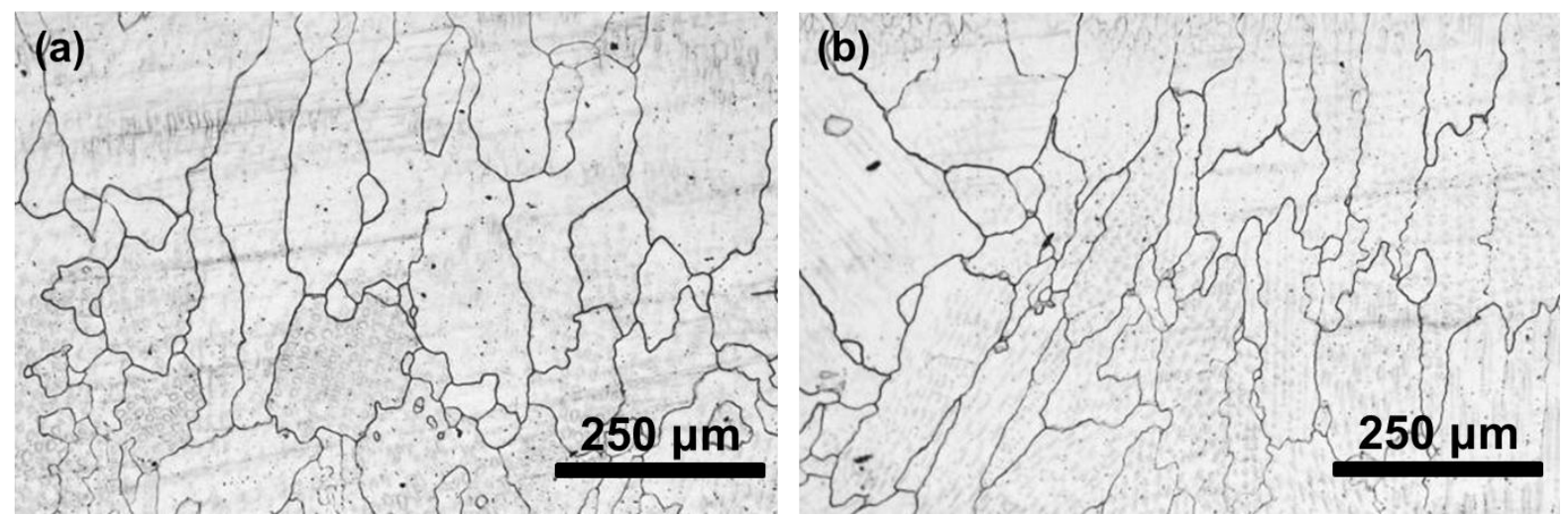

Figure 6. Metallographic structure under different duty cycle, (a) $60 \%$, (b) $20 \%$.

Effect of duty ratio

As shown in figure 6 and table 6, a comparison was conducted to analysis the influence of different duty cycle on weld grain size. In order to control the two heat input same, base current is modified to decrease with the increasing of duty cycle. It is evident that the grain size is smaller with the increasing of duty cycle compared the figure $6 \mathrm{a}$ and $\mathrm{b}$. This is contributed to the action time of peak current and base current. According to the concept of duty cycle, it can be seen that the action time of peak current becomes longer and base current becomes shorter in contrast when the duty cycle increasing. Moreover, both of increase action time of peak current and reduce action time of base current will induce the forceful molten vibration and pressure to make the weld grains finer.

\section{Conclusion}

In present work, the influence of PTIG welding parameters such as peak current, base current, duty ratio and frequency on mechanical properties of filler metal 52M deposition have been investigated. The major conclusions are obtained as follows:

Some joints of Inconel 690 was obtained on employing PTIG and TIG welding technique using filler metal 52M. These two depositions of TIG and PTIG have quite different grain morphology and distribution. By comparison, the grain orientation is dispersed and disorientation, and grain size is smaller in PTIG overlays. 
According to the influence of PTIG welding parameters on grain size, the results reveal that properly increase peak current, pulse frequency and duty cycle can effectively refine the weld grain under the premise of appropriate process parameter interval. However, increase of base current would make grain grow coarser.

The use of appropriate PTIG welding process parameters can produce synergetic effects and significantly improve the quality of Ni-based weldment, thereby reducing the ductility-dip cracking susceptibility in nickel-based alloy.

\section{Acknowledgements}

The present study was supported by the National Natural Science Foundation of China (Grant No. 51504198).

\section{References}

[1] Du J H, Lv X D, Qu J L, Deng Q, Zhuang J Y and Zhong Z Y 2006 Acta Metall. Sin. (English Letter) 19 418-24

[2] Li S Q Zhuang J Y Xie X S and Li B 1998 J. Mater. Eng. 5 26-7

[3] Zhang R, Caruso M, Kiser S, Crum J and Forrester J 2012 NACE - International Corrosion Conference Series 7 5755-69

[4] Jeng S L and Chang Y H 2012 Mater. Sci. Eng. A 555 1-12

[5] Young G A and Paul L NACE 2011.

[6] Pang H T and Reed P A S 2009 Fatigue. Fract. Eng. M. 32 685-701

[7] Ii S A P, Shyam A, Ritchie R O and Milligan W W 1999 Int. J. Fatigue. 21 725-31

[8] Krueger D D Antolovich S D and Stone R H V 1987 Metall. Mater. Trans. A 18 1431-49

[9] Gray G T Williams J C and Thompson A W 1983 Metall. Mater. Trans. A 14 421-33

[10] Wei X Xu M Wang Q Zhang M Liu W Xu J Chen J Lu H and Yu C 2016 Mater. Design. 110 90-8

[11] Manti R Dwivedi D K and Agarwal A 2008 J. Mater. Eng. Perform. 17 667-73

[12] Junaid M Baig M N Shamir M Khan F N Rehman K and Haider J 2017 J. Mater. Process. Tech. 242 24-38

[13] Wang Q Sun D L Na Y Zhou Y Han X L and Wang J 2011 Procedia Engineering 10 37-41

[14] Manti R, Dwivedi D K and Agarwal A 2008 Int. J. Adv. Manuf. Tech. 36 263-9

[15] Manti R and Dwivedi D K 2007 Mater. Manuf. Process. 22 57-61

[16] Liu Y L and Kang S B 1997 J. Mater. Sci. 32 1443-7

[17] Hua C Lu H Yua C Chen J M Wei X and Xu J J 2017 J. Mater. Process. Tech. 239 240-50

[18] Benyounis K Y Olabi A G and Hashmi M S J 2005 J. Mater. Process. Tech. s 164-165 978-85

[19] Akbari D and Sattari-Far I 2009 Int. J. Pres. Ves. Pip. 86 769-76

[20] Reddy G M and Mohandas T 2001 J. Mater. Sci. Lett. 20 721-3

[21] Grill A 1981 Metall. Mater. Trans. B 12 187-92

[22] Zhou F and Qian Y 2004 Chin. J. Mech. Eng. 40 58-61 